\title{
INTRA-SIMULATIVE ECOLOGICAL ASSESSMENT OF LOGISTICS NETWORKS: BENEFITS, CONCEPTS, AND TOOL ENHANCEMENT
}

\author{
Jan Cirullies \\ Christian Schwede \\ Michael Toth \\ Fraunhofer Institute for Material Flow and Logistics \\ Joseph-von-Fraunhofer-Straße 2-4 \\ D-44227 Dortmund, GERMANY
}

\begin{abstract}
Ecology and resource efficiency have achieved high relevance in industry, not only due to their economic effects. Thus, logistics planning is required to contribute to "green" initiatives. However, it still lacks appropriate methods and tools. Simulation represents a well-accepted method in logistics planning, for it can handle dynamics, stochastic effects and a high degree of complexity. In the context of ecological planning, dynamics play an important role as demand peaks are compensated by usually inefficient supporting processes, such as express transportation. OTD-NET is known as an innovative supply chain simulator and is extended by the ecological transportation assessment. This enables the evaluation of green KPIs and - due to the intra-simulative approach - logistics decisions based on ecological balances. In this paper we describe the state-of-the-art on ecological assessment, discuss requirements for its integration into simulation, and explain an implementation approach as well as its benefits by means of a use case.
\end{abstract}

\section{MOTIVATION AND RESEARCH APPROACH}

In the context of sustainability, ecology and resource efficiency are becoming more and more relevant. Sustainability comprises three elements: economy, ecology, and social issues (Brundtland 1987, p. 5). Today, politics and society are aware that our daily life and, due to numerous international agreements (e.g. the United Nations Framework Convention on Climate Change or the Kyoto Protocol) business processes have to change.

Globalization of business processes and, accordingly, of supply chains has brought economic progress and prosperity to different parts of the world. However, this development leads to tremendous additional energy demand and combustion emissions due to the increased use of long distance transport. Major damage may result from the emission of greenhouse gases (GHG), notably the acceleration of climate warming, by excessive human-caused emissions (IPCC 2001, p. 5). Worldwide, the increment of transportation-caused emissions adds up to $69 \%$ above the total GHG emission growth rate (World Resources Institute 2012). Thus, the transportation sector induces $23 \%$ of the worldwide GHG emissions (IPCC 2007 , p. 328) from which $35 \%$ arise from the freight sector (IPCC 2007, p. 330).

Even though some enterprises might not be impressed by ecological impacts, the emission of GHG becomes relevant in a financial sense: as energy is a limited resource, the oil price octupled from the 1990s until 2008, but then decreased to the fivefold due to the economic crisis (Statistisches Bundesamt 2011). Moreover, the introduction of an emission trading scheme in Europe causes direct costs for companies. The EU directive obliges companies to buy quota for the emission of GHG. If a first free quota is exceeded, the company is required to purchase additional certificates from other market participants or to undergo penalties. By the time of its introduction by the directive 2003/87/EG in 2003, the inclusion of 
the transportation sector was already intended. Since 2/2/2009 the EU directive 2008/101/EG has encompassed also air traffic.

Counteractive measures can be divided into technological and organizational approaches. Technological improvements include innovations such as hybrid engines or SkySails (the equipment of cargo ships with sails, cf. http://www.skysails.info), whereas organizational activities refer to logistics planning, e.g. decisions on transport disposition or network node locations. Logistics planning is part of the Supply Chain Management (SCM), which consists of three hierarchic levels: Supply Chain Design (SCD), Planning (SCP), and Execution (SCE). The top level is SCD, which comprises strategic, long-term decisions. Thus, it provides the maximum potential for ecological improvements and is focused in this paper.

Yet, SCD decisions are still made exclusively on a cost and logistics performance base (Hellingrath et al. 2008, p. 460). Energy-related and environmental criteria play only a subordinate role in the network design (Horváth \& Partners 2012) and are balanced - if at all - in a subsequent stage. Due to the expected increasing ecological and, thus, financial relevance of SCD, the classic targets of "costs" and "performance" have to be extended through the inclusion the "ecology" dimension. However, analyses of the German Logistics Association (Bundesvereinigung Logistik, BVL) show that in logistics concepts, tools, and research results are missing in practice (Straube and Pfohl 2008).

Simulation is a common method to support SCD as it allows detailed analyses of highly complex logistics systems considering dynamics and stochastic effects. In order to integrate ecology completely into the SCD planning process, environment based decision making within simulation studies, e.g. transport disposition, has to be enabled. In order to provide a decision basis, an intra-simulative ecological assessment approach is required, as the results must be available at simulation runtime. Therefore, Fraunhofer Institute for Material Flow and Logistics (IML) extended a well-established logistics network simulation tool to include ecological targets. The new features for the intra-simulative assessment necessitated the modification of the whole tool environment.

Accordingly, the aim of this paper is to derive specific requirements for this intra-simulative ecological assessment approach, to present the necessary extensions of a particular simulation tool, and to lineout the concept for an environment-based logistics decision mechanism. The requirements are derived and described in section 2. Then, in section 3, the methodology for emission and energy demand calculations is presented. Its integration into the simulation tool and the resulting benefits are explained in section 4 in the context of a use case. Finally, section 5 summarizes the paper and presents critical remarks as well as an outlook on further research.

\section{REQUIREMENTS FOR THE INTEGRATION OF “GREEN” TARGETS INTO THE SUPPLY CHAIN DESIGN}

\subsection{Requirements Resulting from Classic Logistics Planning}

The design of logistics networks comprises three main tasks (Sucky 2008): (1) decisions on the network structure, (2) the definition of general processes for material, information and money flows between the network nodes, and (3) the dimensioning of locations, processes, relations and resources.

The definition of the network structure relates to the number of logistics-relevant locations, such as plants, warehouses, or distribution centers, as well as their layouts and relations (Sucky 2008). This question is closely related to the number of echelons and to the vertical range of manufacture. The rough definition of processes between the network partners with respect to their locations, i.e. on the network level, is attained through the SCD. Typical logistics processes affect the material and information flow as well as, in rare cases, the money flow (Hellingrath and Eberhardt 2006). The supply chain success depends on the coordination between material and information flows, as indicates by the "information flow rushing ahead" (Cramer 2004, pp. 27-28) and "information replaces stock level" (Kuhn and Hellingrath 2003, p. 653 ) concepts. The dimensioning of required resources is based on the definition of the major processes and comprises the selection of warehousing, transshipment and transportation capacities as well as the respectively applied technology (Sucky 2008, p. 940). 
These decisions usually lead to large investments, and their implementation is hardly reversible (Chopra and Meindl 2010, p. 25). Therefore, several approaches for planning on the SCD level were developed. Typical procedure models, e.g. Klingebiel et al. (2011), Goetschalckx und Fleischmann (2010) and Straube (2011), can be divided into: (1) a phase of data preparation and scope definition, (2) a rough analysis phase, (3) a detailed analysis phase, and (4) a final evaluation including recommendations for action. The rough analysis phase handles the initial data on a rather aggregated level. Suitable and usually applied methods are mathematical optimization or material flow accounting (Seidel 2009, p. 120). Presuming sufficient data aggregation, these static methods require less modeling effort and are able to solve the problem within a reasonable time. The result is a reduced number of potential solution sets that can be analyzed more deeply during the subsequent detailed analysis phase (Seidel 2009, pp. 128-29). In order to ensure an adequate degree of details, this stage considers uncertainty and the dynamic behavior within the supply chain. Consequently, a high degree of complexity has to be handled (Kuhn 2008). Besides the application within the complete process of an SCD procedure model, detailed logistics network analysis becomes relevant, if an existing network is reworked at selected spots. In such a case, a great number of input data from the real network is available and can be included in order to enhance the planning quality. As proven in many studies, discrete event simulation (DES) is an appropriate and widely accepted approach to analyze logistics networks in detail considering extensive input data (Wagenitz 2007, pp. 7677; Tako and Robinson 2011).

\subsection{Requirements for the Ecological Assessment}

As stated in the first section, transportation processes have a major effect on the ecological balance of supply chains and entail a great potential for improvement, for little progress has been made in this field in the past. Thus, the focus for modifications lies on transportation modeling. As the ecological balance of a transport is influenced by various individual properties (e.g. vehicle capacity, capacity usage or payload, transport carrier, etc.), every single vehicle movement has to be assessed individually and assigned to a transport carrier. Data of such a level of detail can only be obtained from simulation.

The introduction of GHG emission certificates leads to an additional influence factor on transport decisions. Whereas former transports dispositions were exclusively based on costs and performance (e.g. acceptable lead time), this method is able to consider emissions and the remaining GHG quota as a decision base. For instance, although transatlantic shipping by sea freight might have delays and cause penalties, emission savings compared to air freight could still make this a more reasonable option. In order to allow such decisions, the GHG balance has to be available at simulation runtime. However, former green analysis approaches apply a post-simulative assessment method, i.e. the calculation of ecological balances after the simulation run based on its results (Reeker, Hellingrath, and Wagenitz 2011). The availability of ecological results at simulation runtime requires, thus, an intra-simulative assessment approach.

Ecological assessment methods are developed permanently, particularly nowadays as "green" is in vogue. To guarantee sufficient adaptability, exchangeability of the logic for ecological assessment has to be guaranteed by encapsulation in a module. However, this necessitates a broad communication interface between the simulator core and the assessment module as a lot of data input and results have to be exchanged.

In summary the integration of ecological objectives into a network simulation tool demands supplementary features compared to classic SCD approaches. The following requirements have to be considered in the research work presented in this paper: (1) mapping of the network structure, processes, and resource dimensions, (2) mapping of stochastic effects and dynamics, (3) handling of a high degree of complexity, (4) representation of single vehicles and their type, (5) ecological balancing at simulation runtime, and (6) module-based ecological assessment logic. In preparation of the integrated simulation concept, the next section describes a suitable methodology for balancing emissions. 


\subsection{Methods and Tools for the Ecological Assessment}

Various methods for the ecological management of inter-organizational supply chains have been developed. Besides well-known examples such as environmental audits (Haker and Löwe 1991), product line analysis (ib.), eco profiling (Benz 1999), and environmental impact assessment (Reeker, Hellingrath, and Wagenitz 2011), life cycle assessment (LCA) has been approved for the evaluation of transportation processes and is widely accepted (Pfohl 2004; Finkbeiner et al. 2006). LCA allows for the systematic perception and assessment of analysis objects, i.e. products or enterprises (Kunhenn 1997). This procedure is standardized by the ISO norm 14040/44 and consists of four sequenced phases (DIN 2006):

1. The goal and scope definition defines system boundaries and the degree of detail.

2. The life cycle inventory analysis (LCI) provides a catalogue of physical process inputs and outputs according to energy footprints. Dimensions entering a process could be energy and raw materials; emissions and the final product are likely to be exiting material.

3. The phase of life cycle impact assessment (LCIA) evaluates the environmental impact of the LCI.

4. Finally, within interpretation phase, the determined balances of the LCI and LCIA are compared to the scope definition, in order to establish the course of action to be taken.

The scope of ecological assessment is already defined by the time the LCA method is applied on a simulation study. Within the LCI phase, the data collection step represents the most complex part (Baumann and Tillman 2009, p. 97). Possible sources are according to Baumann et al. manufacturer data, telephone surveys, experiments, and databases with aggregated, sector-specific average values. As the LCI is based exclusively on virtually existing, simulation-based results, only the last option is viable. Thus, the integration of ecological assessment into simulation takes place specifically on the LCI level and requires the integration of an assessment data source into the simulator.

There are several databases and tools containing necessary data for the integration of ecological assessment into a simulation tool (Hellingrath and Schürrer 2009, p. 21). Generally, these data sources are easy and inexpensive to integrate into existing logistics systems. The exact selection highly depends on the individual use case and its requirements. For the research work presented in this paper, the solution has to be (1) based on scientific research, (2) free of charge, (3) integrable into the existing source code, and (4) methodologically compatible with simulation studies. The last requirement refers to the limited availability of assessment input values from a simulation model compared to reality.

\subsection{Assessment with the European Life Cycle Database}

The European Life Cycle Database (ELCD) is a collection of assessment formulae that fulfills the aforementioned requirements. It is provided by the Joint Research Centre of the European Commission and based on scientifically approved sources (Reeker, Hellingrath, and Wagenitz 2011, p. 152). The ELCD formulae require a straightforward set of input values that can be derived from simulation. As the provided formulae are already prepared with transport-carrier-specific factors, they are easy to implement in program languages. The results are the emissions quantities for well-known substances (e.g. $\mathrm{CO}, \mathrm{CO}_{2}$, methane, or particulate matter) as well as for rather exotic gases such as toluene and xylene.

Furthermore, the ELCD formulae distinguish between the following means of transportation types: trucks $(7.5 \mathrm{t}, 22 \mathrm{t}$, and $40 \mathrm{t}$ of max gross vehicle weight), ocean container ships, trains (electricity- and diesel-driven), cargo planes, as well as other means of transportation that are not considered in this logistics context. The required input values differ between the transportation types: whereas, for instance, ships only require the shipment weight and the transportation distance, truck assessment needs data regarding the max load capacity (according to the truck size), the distribution of pollution classes ("Euro norm") over the utilized truck fleet, and the shares of road types (within town, outside town, highway). 
Figure 1 illustrates through an example the calculation steps for the ELCD formula for a small truck and $\mathrm{CO}_{2}$ emissions. The coefficient for the first calculation step is the differentiating factor between different emission categories.

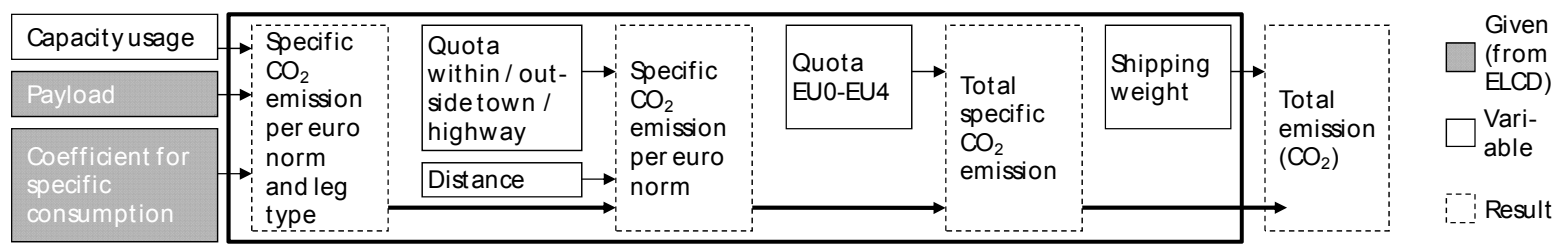

Figure 1: $\mathrm{CO}_{2}$ calculation steps for the ELCD formula for a truck (Cirullies, Klingebiel, and Scavarda 2011)

Therefore, the ELCD formulae are highly suitable to be implemented in a programming language, i.e. as a method. This requires a precisely defined set of parameters, that are summarized in Table 1:

Table 1: Parameters of the ELCD formulae.

\begin{tabular}{|l|c|c|c|c|c|c|c|}
\hline \multicolumn{1}{|c|}{ Parameter } & $\begin{array}{c}\text { Container } \\
\text { Ship }\end{array}$ & $\begin{array}{c}\text { Cargo } \\
\text { Plane }\end{array}$ & $\begin{array}{c}\text { Train } \\
\text { (Diesel) }\end{array}$ & $\begin{array}{c}\text { Train } \\
\text { (Electric) }\end{array}$ & $\begin{array}{c}\text { Truck } \\
\mathbf{7 . 5 ~ t}\end{array}$ & $\begin{array}{c}\text { Truck } \\
\mathbf{2 2 ~ t}\end{array}$ & $\begin{array}{c}\text { Truck } \\
\mathbf{4 0} \text { t }\end{array}$ \\
\hline Distance & $\mathrm{x}$ & $\mathrm{x}$ & $\mathrm{x}$ & $\mathrm{x}$ & $\mathrm{x}$ & $\mathrm{x}$ & $\mathrm{x}$ \\
\hline Shipping weight & $\mathrm{x}$ & $\mathrm{x}$ & $\mathrm{x}$ & $\mathrm{x}$ & $\mathrm{x}$ & $\mathrm{x}$ & $\mathrm{x}$ \\
\hline Capacity usage & - & $\mathrm{x}$ & $\mathrm{x}$ & $\mathrm{x}$ & $\mathrm{x}$ & $\mathrm{x}$ & $\mathrm{x}$ \\
\hline Share "within town" & - & - & - & - & $\mathrm{x}$ & $\mathrm{x}$ & $\mathrm{x}$ \\
\hline Share "outside town" & - & - & - & - & $\mathrm{x}$ & $\mathrm{x}$ & $\mathrm{x}$ \\
\hline Share "highway" & - & - & - & - & $\mathrm{x}$ & $\mathrm{x}$ & $\mathrm{x}$ \\
\hline Share "Euro norm 0" & - & - & - & - & $\mathrm{x}$ & $\mathrm{x}$ & $\mathrm{x}$ \\
\hline Share "Euro norm 1" & - & - & - & - & $\mathrm{x}$ & $\mathrm{x}$ & $\mathrm{x}$ \\
\hline Share "Euro norm 2" & - & - & - & - & $\mathrm{x}$ & $\mathrm{x}$ & $\mathrm{x}$ \\
\hline Share "Euro norm 3" & - & - & - & - & $\mathrm{x}$ & $\mathrm{x}$ & $\mathrm{x}$ \\
\hline Share "Euro norm 4" & - & - & - & - & $\mathrm{x}$ & $\mathrm{x}$ & $\mathrm{x}$ \\
\hline
\end{tabular}

These parameters are obtained from the events (e.g. a transport disposition or transport arrival) during simulation. In order to fulfill requirement 0 (balancing at simulation runtime), the ELCD formulae have to be linked to the simulator core. This integration into an exemplary simulation tool is described in the following section in context of a use case.

\section{APPLICATION OF ECOLOGICAL ASSESSMENT IN LOGISTICS SIMULATION}

\subsection{Use Case Scenario: A Global Automotive Supply Chain}

A typical scenario demonstrating the interdependency of logistic decisions is derived from the use case of a current project within the automotive industry. A European car manufacturer is currently producing a model exclusively in Argentina. Soon the additional production will ramp up in Europe. Suppliers are based worldwide, but concentrated in South America and Europe. Thus, the cargo comprising roughly 600 parts, components, modules, and aggregates is consolidated and packed in centers within these two regions. Although applied multi-sourcing strategies allow short procurement distances, in some cases parts need to be shipped from a different continent, which necessitates multimodal transport through a distance of about $13000 \mathrm{~km}$. Typically, the main carriage is performed by ship and the pre- and oncarriage by truck. However, such a long supply chain entails the risk of various disturbances, e.g. a change on demand, and, thus, requires a certain flexibility potential. However, this potential to fulfill the request- 


\section{Cirullies, Schwede, and Toth}

ed logistic performance may have negative economic and ecological impacts: the usage of express air transportation reduces the main carriage lead time from about three weeks to three days.

New network design decisions, such as the establishment of a second production site on a different continent, provide an enormous scope for action, as well as potential for improvements, and increase the network complexity significantly. In this context, a central question arises: to which plant shall an order be assigned. This involves data, such as the distribution destination, plant capacities, availability of parts according to the customer's specifications, supplier capacities in Europe or South America, and transport capacities. The decision may be evaluated based on performance considerations, e.g. what order-todelivery lead time is acceptable, on supply, production, and distribution costs, and on the ecological balance of transports. The latter depends heavily on the location of the suppliers and customers.

Evidently, this use case is subject to a high degree of complexity. The described effects on the supply chain change over time and the best way to model is through stochastic distributions. Thus, simulation is a suitable method to analyze this logistics network and to identify risks and potentials in depth.

\subsection{Introduction of the Applied Simulation Tool}

There are various appropriate simulation tools for the analysis of logistics systems (Cirullies, Klingebiel, and Scavarda 2012). Similar to the ecological assessment databases, their suitability depends on the respective case and its requirements. OTD-NET ("order-to-delivery network simulation") is a discrete-event simulation (DES) environment that is specialized on the evaluation of multi-echelon supply chains (Wagenitz 2007). The simulation suite was developed by Fraunhofer IML and provides a holistic approach for modeling and simulating complex production and logistics networks (Kuhn and Hellingrath 2006, p. 306). This tool delivers detailed insights into information and material flows, stock levels, network stability and flexibility, boundary conditions and restrictions.

The OTD-NET suite consists of the Graphical Modeling Environment (GME), an SQL database, and the simulator itself (cf. Figure 2 for an overview, with the inclusion of the described enhancements). The initial database comprises the definition of the OTD-NET classes for the modeling of the network and product structure, and planning details. Typical probability distributions or constant values are used to specify parameters, e.g. lead times, routing decisions, and installation rates of properties. The GME is used to create objects from these classes and is able to build up models with high complexity. Subsequently, the simulator reads the complete model from the database, performs the parameterized simulation run(s), and writes the results to the result tables of the database. The simulator is equipped with an interface for DLL (dynamic link library) files that provide complex influence on the model.

Thus, OTD-NET already fulfills the aforementioned requirements one to three. The network structure, products, and processes can be modeled in detail. The definition of relevant parameters by a probability distribution ensures the mapping of stochastic effects and DES ensures dynamics. Furthermore, DES and the structured representation of the model in the GME allow building highly complex simulation models. However, requirements four to six are not met by this tool. Indeed, vehicles are represented in OTD-NET, but they are not assigned to a specific type, e.g. to an ELCD type. Moreover, there is no integrated ecological assessment logic. This gap necessitates certain extensions which will be described in the following section.

\subsection{Description of the Applied Extensions}

The OTD-NET suite has to be extended at multiple spots. At the database level, new classes and attributes have to be defined. As DLLs can be regarded as flexible modules connected to the simulation core, they are predestinated to encapsulate the ecological assessment logic. The simulator has to "learn" how to collect the required assessment parameters at runtime and how to transfer them to the assessment module. The concept of OTD-NET and the necessary extensions for the ecological assessment are depicted in Figure 2. 


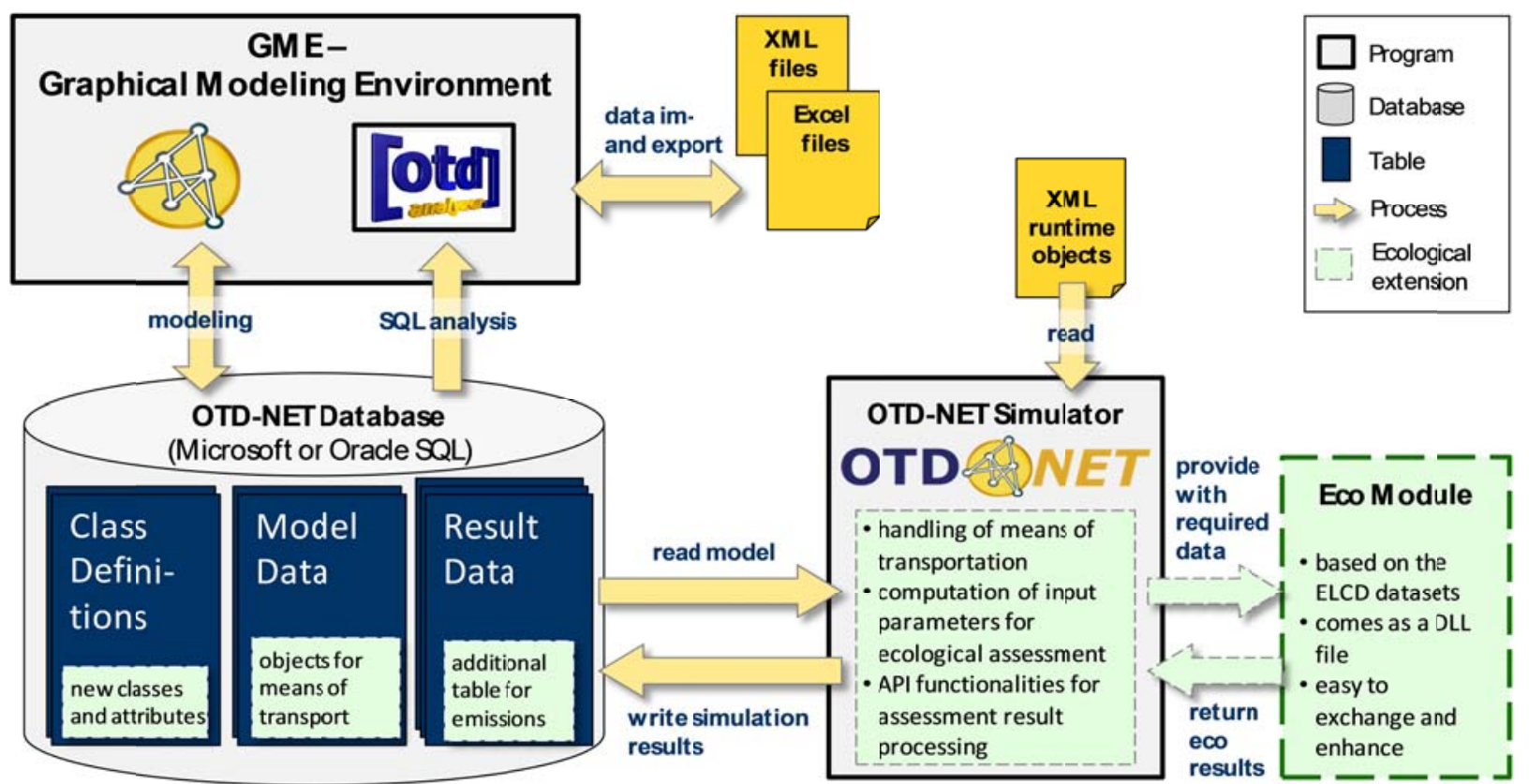

Figure 2: Scheme of the concept of OTD-NET and the ecological extensions

\subsubsection{Database Extensions}

The data concept for the ecological assessment has to be integrated into existing classes and result tables in order to allow the modeling of environment-related parameters and to store the according calculation results. The original classes, as well as the result tables, were described by Wagenitz (2007).

The complements of the classes MeansOfTransportation (MoT) and RouteInformation are directly related to transportation processes. The latter has been extended by the new attributes QuotaWithinTown, QuotaOutsideTown, and QuotaHighway, containing a float number for the assessment of truck transport. The MoT class has been extended by two attributes: ELCDType is an enumeration value (enum) that corresponds to the ELCD types introduced in subsection 3.2. The second attribute EuroNorm is also an enum and comprises the values "Euro_norm_0" through "Euro_norm_4" as well as "none".

Further database class modifications refer particularly to the elements of the product structure (products, parts, and properties), as well as to their dimensions and containers. As all of the product-structurerelated classes have to be extended to comply with the requirements for ecological assessment, they are complemented by the attributes PartDimensions and MoTSpecDimensions. The first parameter references the new class DimensionsOfGoods that includes the attributes TransportationWeight, CargoWeight, and Volume. These float values are necessary to evaluate economic and ecological effects. The transportation weight represents the physical weight, whereas the cargo weight refers to the weight that is subject to freight charge. These two weight parameters differ if the cargo volume falls below a specific value. The MoT specific dimensions allow applying different weight declarations depending on the mean of transportation. Thereby, cargo may stay in the same (virtual) container on different vehicles, although their actual packaging changes, e.g. from pallets to TEU containers. The MoTSpecDimensions attribute connects a MoT type to a DimensionsOfGoods object. Finally, the already existing container class has been extended by the inclusion of the attributes TareContainer, Volume, and VolumeEmptyContainer. Particularly the tare of a container has to be added to cargo that is subject to ecological assessment.

On the result table side, a new table called OUT_Eco has been introduced. This table takes the primary keys (TRTIID and DCL_ID, both integer) from the OUT_Transports table. A transport is identified by the TRT_ID and may range over more than one distribution channel (DC). The attribute ELCD_Type contains the enum value that was set at the according input parameters. The two succeeding attributes (To- 
tal_weight and Total_volume, both float) store the weight and volume of the entire transport. The last attributes (CO2, $\mathrm{CO}$, Benzene, $\mathrm{NOx}, \ldots$, all float) contain the emissions caused by the transport on one DC.

\subsubsection{Enabling and Validating the Simulation Tool}

The database modifications are processed by the OTD-NET suite, which is programmed in $\mathrm{C}++$. As described in detail in the previous sections, ecological assessment requires a great number of input parameters. This requires the simulation core to provide this data to the assessment component. Figure 3 gives an overview on all modifications in the OTD-NET and DLL source code. Both consist of a core unit as well as an interface (dashed line) called Scripting Host on the simulator side, and of OTD API on the DLL side. Both interface parts provide a dispatcher which receives function calls from the respective opposite side.

As shown in Figure 3, the ecological extension requires mechanisms to (0) create the empty result table at simulation start and (1) call the assessment logic whenever a transport arrives at the end of a DC to initialize the calculation of emissions by OnEndTransport. This class first (2) collects required information about the concerning transport, then runs the appropriate ELCD assessment method, and finally (3) writes the results to the data table created in the initialization phase.

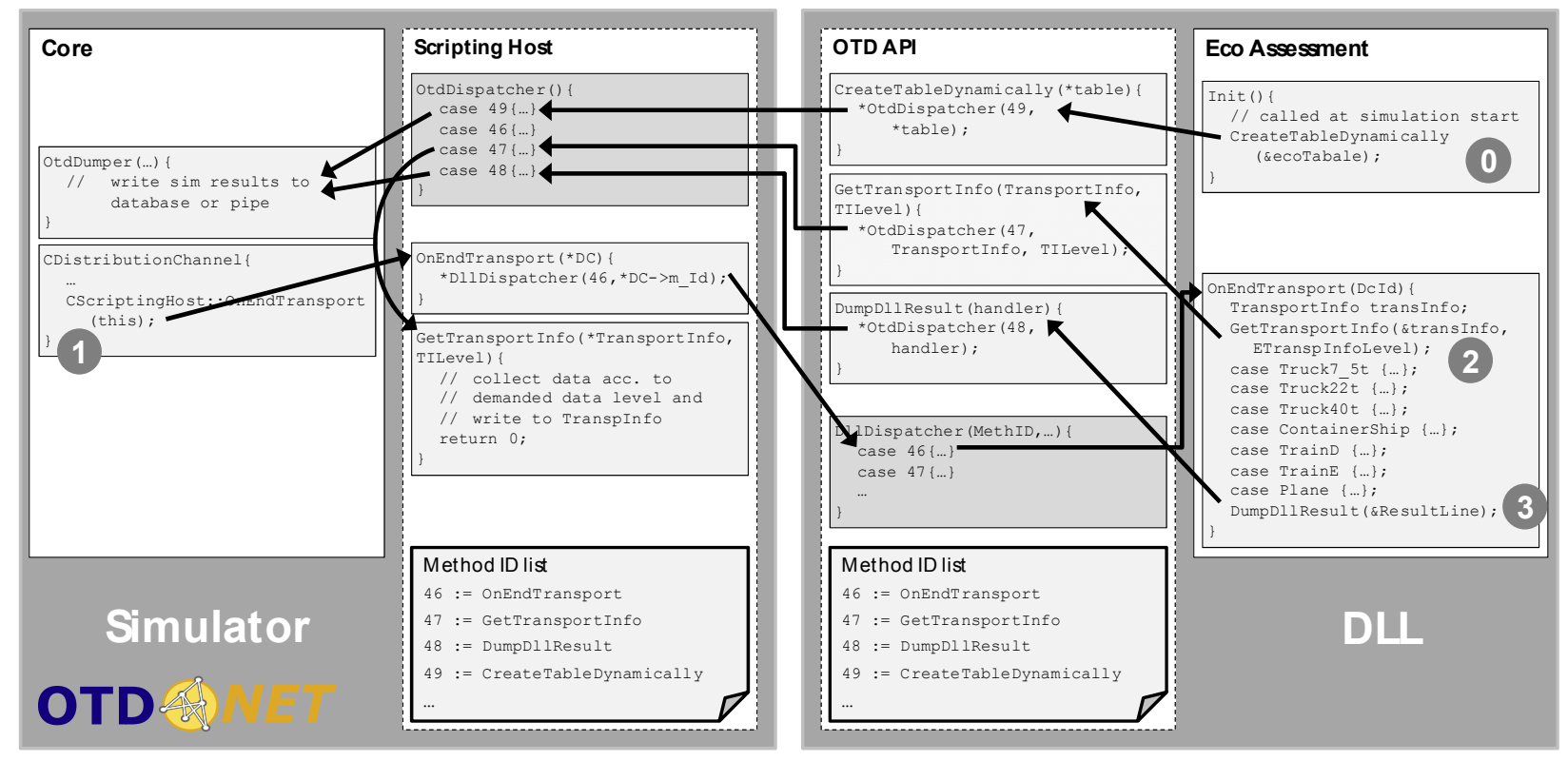

Figure 3: Modifications for binding the eco module on the OTD-NET simulator

To ensure that the eco module works correctly, the functionalities 0 through 3 have to be verified and validated. As the steps 0,1 and 3 are rather trivial, the major focus lies on the data collection and calculation at runtime (step 2). Because OTD-NET has been approved in many projects and the simulation core affecting simulation runs has not been modified, the results provided by the simulator can be considered as valid. Thus, data collection and result calculation are crucial. The applied (deterministic) test model contains a set of relations combining all means of transportation, product types, route types, Euro norms, and different load factors. These test model results have been compared to a manual calculation. With a deviation of $0 \%$, the mechanisms for data collection and result calculation are valid. 


\subsubsection{Routing Concept According to Ecological Criteria}

Yet, decisions in logistics network design, particularly with respect to supporting tools and methods, are currently based exclusively on costs and performance targets as explained in section 1. Moreover, in OTD-NET, decisions are based on static criteria, e.g. product properties, or dynamic criteria, e.g. urgency of deliveries. Ecological dimensions are, thus, being left out. As a result of the intra-simulative integration of the ecological assessment module, only a few changes on the simulator and database are necessary to enable ecologically based routing decisions.

Conceptually, routings in OTD-NET consist of a routing table that references an arbitrary number of routings. These routings are succeeded by other routing tables or normal process elements, e.g. DCs, buffers, plants, and markets. The selection of a routing relies on probability distributions or on search patterns that activate the routing entry if they match certain product qualities, the product destination, the demand for an express transport or other constraints.

Thus, the pattern class has to be completed by the attribute EmissionQuota, a reference on the new class EmissionPattern. This class requires three attributes: the first one is a string vector called EmissionType, that is able to store a list of emission names that are written to the result stream, e.g. "CO2", "CO", and "Benzene". The second attribute called EmissionQty is a vector of float values that must be of equal length as the EmissionType list, and contains emission quotas in the unit "kg". Thus, vector entries in both lists are arranged in pairs according to their position in the vector. The third attribute IncludeAllQuotas is a Boolean value that indicates whether all emission quotas have to be reached to match the pattern or only one. Accordingly, the simulator has to support the routing concept by logging the total sum of determined emission balances and considering the aforementioned extensions of the search patterns.

\subsection{Benefits for the Ecologically Integrated Supply Chain Design in the Use Case}

For the evaluation of the global supply chain, the modifications of OTD-NET bring two major benefits: First, the OTD-NET suite is able to assess scenarios according to ecological targets. Whereas this was before only subsequently possible, now the third dimension is already included in the simulation results. Second and more importantly is the integration of ecological indicators as a routing basis. This allows making logistic decisions according to the available emission quota. The use of air cargo on the intercontinental main carriage is reduced if a certain total emission level of the logistics system is reached. This will lead to potentially longer lead times and the order assignment to a closer plant with a later start of production may be competitive.

Figure 4 describes an example for this application. The sketch shows a routing table with two routing entries respectively succeeded by a DC. The ship routing is the first entry and, according to OTD-NET concepts, tested at first. The routing references the "Search Pattern Sea Cargo", which uses the new attribute and class for emissions. The emission pattern object called "EP GHG" contains a list of greenhouse gases and the according quotas that the company is willing to emit. As soon as one emission limit is reached (attribute "Include All Quotas" = false), the emission pattern and, therefore, the search pattern are matched.

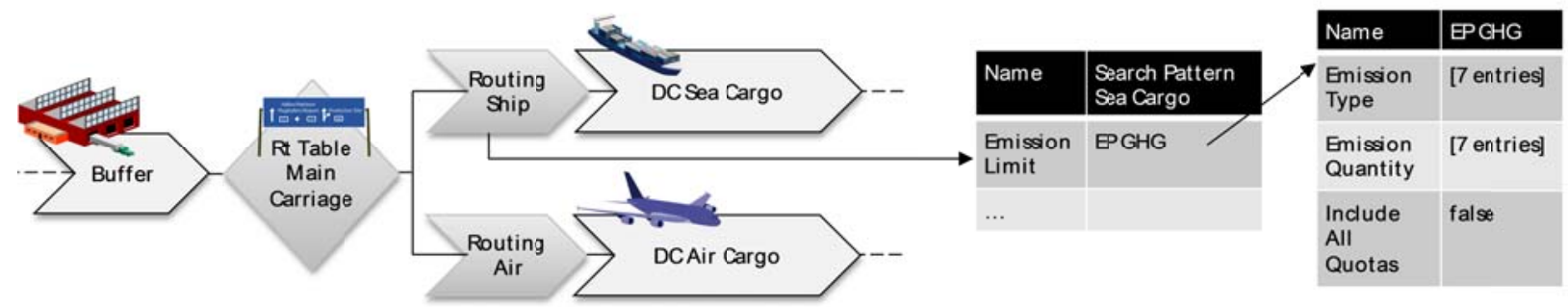

Figure 4: A sample routing concept based on emissions 
This new concept provides full integration of transport emission as ecological targets into simulation. The holistic approach of OTD-NET combining production planning, supplier interaction and distribution processes enables making decisions in production and transport disposition based on emissions. The applied analysis method - simulation - ecologically allows relevant input parameters to be individually calculated for each transport.

\section{CONCLUSION AND DISCUSSION}

The logistics network simulation tool OTD-NET has been extended and is now able to determine an LCI balance for transportation processes in accordance to LCA. The innovative intra-simulative assessment approach offers the possibility to take decisions, e.g. transport disposition, according to ecological objectives. As simulation is a common method for the detailed analysis phase, this research work contributes to fill the gap of missing tools for the ecology-oriented design and planning of logistics networks.

Initially, six requirements for the enhancement were identified. Whereas the first three requirements were already met by the selection of the assessment method (discrete-event simulation) and tool (OTDNET), major modifications were necessary to fulfill the requirements four to six. The alterations have been made on the database level (new classes and attributes), in the simulator core (results processing and DLL interface), and particularly in the DLL module. Methodologically and with regard to the assessment formulae, however, there is still potential for improvements.

On the one hand, the European norm draft EN 16258 recommends an exact methodology for the ecological assessment of transportation processes. Its central idea is to establish "Vehicle Operation Systems" (VOS), i.e. the complete loop of a vehicle that contributes to a transportation process as well as the onand off-loaded cargo. Although this method allows the detailed assignment of energy consumption and emissions to a product, it requires an enormous number of input data which is too complex to be obtained from a logistics simulation model. In order to implement the LCA method as completely as possible, the LCIA phase must be also considered. The intra-simulative aggregation of flow balances by adding the impact of the emissions (e.g. $\mathrm{CO}_{2} \mathrm{e}$ ) would offer further opportunities for the assessment.

On the other hand, the ELCD has to be considered as a sample assessment basis. In fact, ELCD has been already overcome by datasets that are more up to date and involve further relevant input factors, e.g. route profile (uphill/downhill sections) or even the driver's habits. However, the modular concept of the ecological assessment in OTD-NET is rather simple to be included and, thus, this tool is able to be adapted to new requirements quite easily.

Besides the application in network design simulation studies, the OTD-NET simulator is appropriate for further purposes, notably for Logistics Assistance Systems (LAS), i.e. software suites that aggregate enterprise data from various information sources, offer an integrated view, and assess virtually operative decisions. For the assessment step, the use of the aforementioned simulation tool is also highly suitable. In addition, OTD-NET is recommended for application in the detailed analysis phase of SCD procedure models (cf. subsection 2.1) that integrate green objectives.

\section{REFERENCES}

Baumann, H., and A.-M. Tillman. 2009. The hitch hikers's guide to LCA: An orientation in life cycle assessment methodology and application. Lund: Studentlitteratur.

Benz, M. 1999. "Umweltverträglichkeit von Transportketten.” Dissertation, TU Berlin.

Brundtland, H.C. 1987. Closing Ceremony of the Eighth and Final Meeting of the World Commission on Environment and Development. Tokyo, Japan

Chopra, S., and P. Meindl. 2010. Supply Chain Management: Strategy, Planning, and Operation. Upper Saddle River, New Jersey: Pearson Education.

Cirullies, J., K. Klingebiel, and L. F. Scavarda. 2011. "Integration of Ecological Criteria Into the Dynamic Assessment of Order Penetration Points in Logistics Networks." In ECMS 2011: Jubilee Conference. Edited by T.. Burczynski, J. Kolodziej, A. Byrski, and M. Carvalho, 608-15. 
Cirullies, J., K. Klingebiel, and L. F. Scavarda. 2012. “A Conceptual Framework for Green Supply Chain Design." In ICIEOM.

Cramer, F.-S.. 2004. "Entwicklung eines Modells zur transponderbasierten Informationsflussgestaltung in Produktionsnetzen." Dissertation, Technische Universität Dortmund.

DIN. 2006. Umweltmanagement - Ökobilanz - Anforderungen und Anleitungen 13.020.10, no. EN ISO 14044:2006. Berlin: Beuth Verlag GmbH.

Finkbeiner, M., A. Inaba, R. Tan, K. Christiansen, and H.-J. Klüppel. 2006. "The New International Standards for Life Cycle Assessment: ISO 14040 and ISO 14044." The International Journal of Life Cycle Assessment 11 (2): 80-85.

Goetschalckx, M., and B. Fleischmann. 2010. "Strategic network design." In Supply chain management und advanced planning: Konzepte, Modelle und Software. Edited by H. Stadtler, 135-52. Berlin: Springer.

Haker, W., and W. Löwe. 1991. "Umwelt-Audit: Ist-Aufnahme des betrieblichen Umweltschutzes." In Die Organisation des betrieblichen Umweltschutzes. Edited by H. W. Adams, 195-209. Blick durch die Wirtschaft. Frankfurt am Main: Frankfurter Allg. Zeitung.

Hellingrath, B., and S. M. Eberhardt. 2006. "Werkzeuge für das Supply Chain Design." In Software in der Logistik: Marktspiegel. Edited by M. ten Hompel. 1st ed.., 94-97. Logistik Praxis. München: Huss-Verl.

Hellingrath, B., T. Hegmanns, J.-C. Maaß, and M. Toth. 2008. "Prozesse in Logistiknetzwerken: Supply Chain Management." In Handbuch Logistik. Edited by D. Arnold, K. Furmans, H. Isermann, A. Kuhn, and H. Tempelmeier. 3th ed., 459-86. Berlin, Heidelberg: Springer-Verlag.

Hellingrath, B., and S. Schürrer. 2009. "Energieeffizienz und Umweltbilanz von Supply Chains." In Software in der Logistik: Klimaschutz im Fokus. Edited by M. ten Hompel. 1st ed., 16-21. Logistik Praxis. München: Huss-Verl.

Horváth \& Partners. 2012. "Supply Chain Management auf dem Prüfstand: Intelligente Verknüpfung von Strategien, Prozessen und Controlling zur Steuerung der Supply Chain." Logistik für Unternehmen (1/2): 20-21.

IPCC. 2001. "Climate Change 2001: Summary for Policymakers - A Report of Working Group I of the Intergovernmental Panel on Climate 2001. http://www.grida.no/climate/ipcc_tar/vol4/english/pdf/wg1spm.pdf.

IPCC. 2007. "Transport and its infrastructure." In Climate Change 2007: Mitigation - Contribution of Working Group III to the Fourth Assessment Report of the Intergovernmental Panel on Climate Change. Edited by B. Metz, O.R Davidson, P.R Bosch, R. Dave, and L.A Meyer, 323-386. Cambredge, New York: Cambridge University Press.

Klingebiel, K., L. F. Scavarda, H. Winkler, and A. Wagenitz. 2011. "Logistikkompetenz in Brasilien: Transfer erprobter logistischer Methoden in einen Entwicklungsmarkt." Industrie Management.

Kuhn, A. 2008. "Simulation großer Logistik-Netze." In Schriftliche Fassung der Vorträge zum Fertigungstechnischen Kolloquium am 10. und 11. September in Stuttgart, 1-20. Stuttgart: Ges. für Fertigungstechnik.

Kuhn, A., and B. Hellingrath. 2003. "Auftragsmanagement in Netzwerken: Supply Chain Management." In Neue Organisationsformen im Unternehmen. Edited by H.-J. Warnecke, E. Westkämper, and H.-J. Bullinger. 2nd ed., 644-70. Berlin, Heidelberg: Springer.

Kuhn, A., and B. Hellingrath. 2006. "Instrumente und Methoden für das Kooperationsmanagement in Logistiknetzwerken.” In Innovative Kooperationsnetzwerke. Edited by A. Barth, 295-312. Wiesbaden: Deutscher Universitäts-Verlag.

Kunhenn, H. 1997. "Ökobilanzen: Ursachen, Ausprägungen und Auswirkungen von Freiräumen auf den Einsatz von Ökobilanzen durch Unternehmen.” IAI Institut für Angew. Innovationsforschung, RuhrUniversität Bochum.

Pfohl, H.-C. 2004. Logistikmanagement: Konzeption und Funktionen. 2., vollständig überarbeitete und erweiterte Auflage. Berlin, Heidelberg: Springer-Verlag Berlin Heidelberg New York. 
Reeker, C., B. Hellingrath, and A. Wagenitz. 2011. "Bewertungsansatz zur ökologischen Gestaltung automobiler Logistiksysteme im Werksumfeld von Produktionsstandorten." In Supply Management Research: Aktuelle Forschungsergebnisse 2011. Edited by R. Bogaschewsky, M. Eßig, R.r Lasch, and W. Stölzle, 139-68. Wiesbaden: Gabler.

Seidel, T. 2009. Ein Vorgehensmodell des softwareunterstützten Supply Chain Design. Unternehmenslogistik. Dortmund: Verl. Praxiswissen. Tech. Univ., Diss--Dortmund, 2008.

Statistisches Bundesamt. 2011. "Preise auf einen Blick." Wiesbaden.

Straube, F., S. Doch, A. Nagel, O. Ouyeder, and S. Wuttke. 2011. "Bewertung öko-effizienter Logistikstrukturen in global agierenden Wertschöpfungsketten.” In Flexibel - sicher - nachhaltig. Edited by T. Wimmer and T. Grosche, 201-27. Hamburg: Dt. Verkehrs-Verl.

Straube, F., and H.-C. Pfohl. 2008. Trends und Strategien in der Logistik: Globale Netzwerke im Wandel ; Umwelt, Sicherheit, Internationalisierung, Menschen. Hamburg: Dt. Verkehrs-Verl.

Sucky, Eric. 2008. "Netzwerkmanagement." In Handbuch Logistik. Edited by D. Arnold, K. Furmans, H. Isermann, A. Kuhn, and H. Tempelmeier. 3.th ed., 934-45. Berlin, Heidelberg: Springer-Verlag.

Tako, A. A., and S. Robinson. 2011. "The application of discrete event simulation and system dynamics in the logistics and supply chain context." Decision Support Systems, 802-15.

Wagenitz, A. 2007. "Modellierungsmethode zur Auftragsabwicklung in der Automobilindustrie." Dissertation, Technische Universität Dortmund.

World Resources Institute. 2012. Climate Analysis Indicators Tool. Washington, DC.

\section{AUTHOR BIOGRAPHIES}

JAN CIRULLIES studied both logistics and business science at the Technical University of Dortmund, Germany. As a student assistant he gained practical knowledge in the field of supply chain simulation at Fraunhofer IML, Dortmund. Since 2009, he is doctoral fellow of the NRW Graduate School of Energy Efficient Production and Logistics, Dortmund, and working at Fraunhofer IML focusing on the dynamic assessment of logistics networks by ecological criteria. His e-mail address is jan.cirullies@iml.fraunhofer.de.

CHRISTIAN SCHWEDE is leader of the group of Logistic Assistance Systems and Digital Logistics at the Department Supply Chain Engineering of Fraunhofer IML in Dortmund. He is working for the institute as a scientific assistant since 2007, working in the research area of logistic network simulation and optimization with a special focus on automotive industry. Besides the research his work includes industrial consultancy and software development projects in this and related fields. His e-mail address is christian.schwede@iml.fraunhofer.de.

MICHAEL TOTH is scientist and head of the Supply Chain Engineering department at Fraunhofer IML in Dortmund, one of the biggest logistic research institutes worldwide. He has been working for IML since 2003 and is responsible for industry and research projects, especially in the areas automotive, supply chain management and simulation, demand and capacity planning, and Logistic Assistant Systems. His e-mail address is michael.toth@iml.fraunhofer.de. 